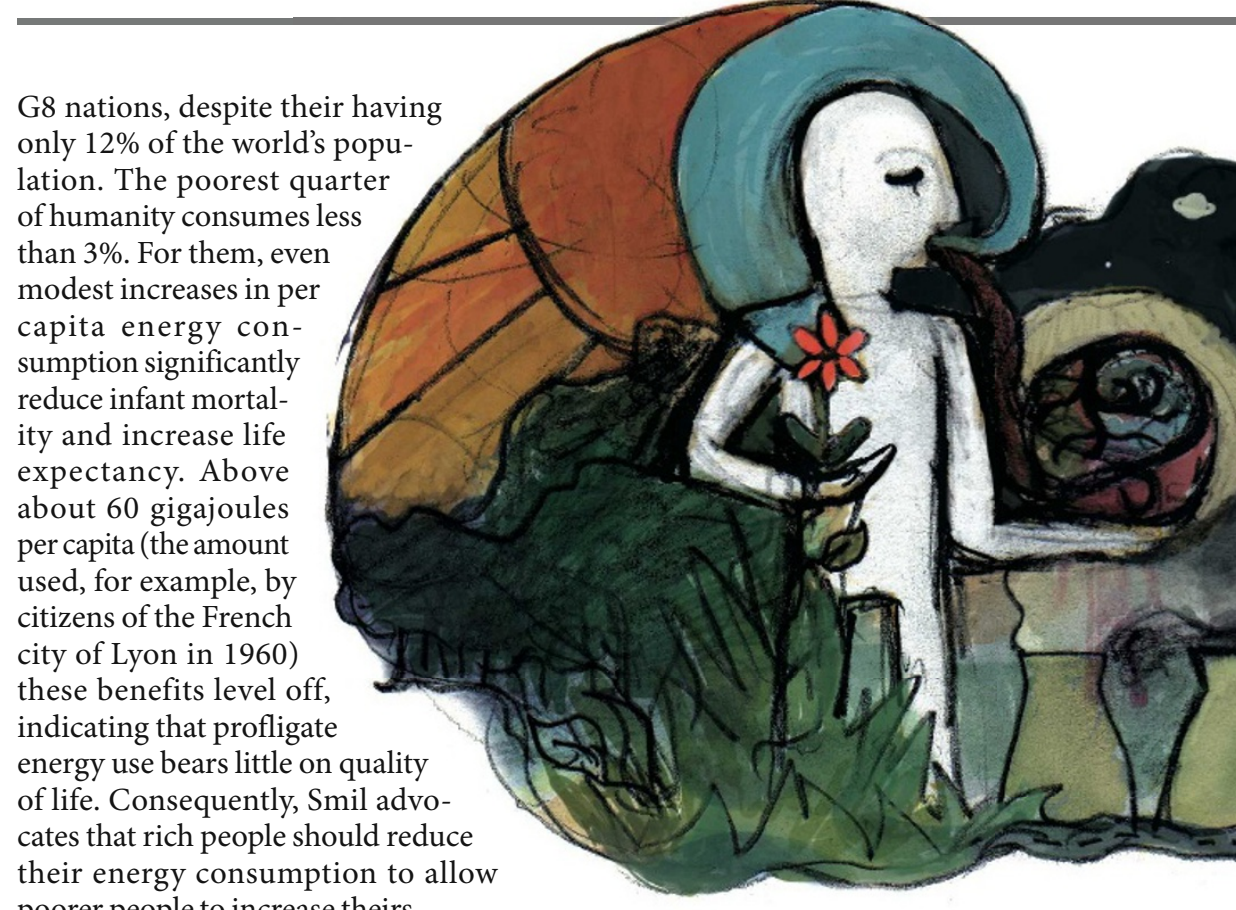
poorer people to increase theirs.

Today's high-technology societies mostly rely on fossil fuels. These concentrated reserves of stored ancient sunlight - the remnants of past organisms - are finite, and the products of their combustion have undesirable consequences, from respiratory problems to climate change. Smil argues that we should stop the seemingly endless growth of energy consumption while we switch to cleaner and more sustainable sources of power.

In the long term, Smil's solution is solar power, because the total supply of sunlight at Earth's surface exceeds current global fossilfuel consumption by more than a thousand times. Until then, he supports a careful transition away from fossil fuels and points out that carbon capture and storage have limited capacity. He dismisses most renewable energy sources because their power densities are too low to supply the needs of the present global population, let alone future ones. This includes first-generation biofuels, where their poor energy returns could ultimately mean feeding cars in place of people. In Energy in Nature and Society, Smil contends that power from nuclear fission would become limited by uranium supply until a viable commercial fast-breeder reactor is available, and fusion power is too far from commercial deployment. All of which implies a difficult transition period involving substantial carbon dioxide emissions and climate change.
If we are to have a long and happy future on this planet, we need to follow life's example and find more efficient ways of extracting free energy from sunlight. But energy isn't everything. The successful major transitions between past biospheres also required increases in material recycling, because the organisms capturing energy built their

\section{What Is Life? Investigating the Nature of Life in the Age of Synthetic Biology by Ed Regis}

\section{Steven Benner}

Book titles should display ambition, and Ed Regis' latest certainly does that. Implicit is progress between two areas of biology. What Is Life? recalls Erwin Schrödinger's famous book of the same name that encouraged many physicists to begin working in molecular biology in the 1940s; synthetic biology is the fast-moving area today.

The term synthetic biology was coined in 1974 by Waclaw Szybalski to describe the modification of organisms by adding and subtracting genes. In those days it was known as
Farrar, Straus \& Giroux: 2008. 208 pp. \$22

bodies from elements whose supplies were restricted. In contrast, to maintain our present high level of energy transformation in society, we increase the inputs of many elements, mostly by mining them from finite reserves in Earth's crust.

We thus perturb global biogeochemical cycles. A wiser strategy in the long term would be to increase the recycling of materials that accompany the capture and use of energy.

I would like to encourage Smil to strengthen

this link between energy processing and material cycling in the next edition of his book, and to address whether the combination of solar power and recycling might allow energy transformation by humans and the biosphere to grow again. For now, the energy required to read this comprehensive and scholarly tome is extremely well spent.

Tim Lenton is professor of Earth system science in the School of Environmental Sciences, University of East Anglia, Norwich NR4 7TJ, UK.

\title{
Biology from the bottom up
}

'genetic engineering' or 'recombinant DNA technology'. By altering the genes, the organisms act in new ways.

At the time, Szybalski's synthetic biology prompted fear. The city of Cambridge, Massachusetts, banned genetic engineering entirely. A conference was convened in Asilomar, California, to decide how to manage the new ability to create artificial organisms.

Three decades of experience have shown the risks to be negligible but the rewards enormous. Today, the field of synthetic biology is expanding, spawning new university departments, such as the one that hosts Jay Kiesling's laboratory at the University of California at Berkeley in which bacteria are created to produce
Francis Crick: Discoverer of the Genetic Code by Matt Ridley (Harper Perennial, $€ 7.99$ ) The story of Francis Crick extends beyond the discovery of DNA. Matt Ridley's biography details how he came to study biology, sets in context his controversial ideas and gives a glimpse into the character of one of the most famous scientists of the twentieth century.

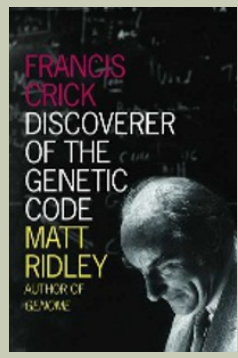

The Music of Life: Biology Beyond Genes by Denis Noble (Oxford Univ. Press, $€ 7.99$ ) Instead of taking a blinkered view based on genes and genomes, Denis Noble argues, we must realize that life is a process. To see its workings, we should look at interactions on every level - genes, cells, the body, systems and the environment.

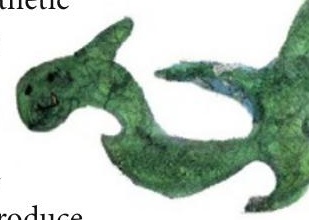

(n) 
pharmaceutical intermediates. Craig Venter, a driver of innovation in contemporary genomics, and whose personal genome can be found on the Internet, is going further by proposing reorganization of the natural parts of natural genomes. Some of these restructured microbes are so scrambled that they deserve to be viewed as new species.

The remit of synthetic biology has widened as other researchers have adopted the label. In 2000, Eric Kool of Stanford University, California, used it to describe the construction by chemists of unnatural molecules that can operate within natural living systems. To Drew Endy and others at the Massachusetts Institute of Technology, it means the process of creating, mostly by modifying existing biomolecules, units that can serve as interchangeable parts in larger assemblies. Stephen Wolfram and others view "artificial life" as a computer program that yields output behaviour that is analogous to the behaviour of living systems.

What is Life? captures these differing perspectives well. As expected from a science writer with Regis' record, the book is an easily readable review of the development of contemporary biology, including the first-generation model for DNA structure, the foundation of metabolism, and the elucidation of the genetic code. Furthermore, it captures interactions between scientists who approach synthetic biology differently, providing a brief and entertaining glimpse into the competitive aspects of modern science. For example, one experimenter (Norman Packard of Protolife, based in Venice, Italy), trying to get a real cell made out of real chemicals to work in a real laboratory, sets these activities above trying to write computer programs that simulate parts of biological chemistry. Another (Francis Collins, who heads the National Human Genome Research Institute in Bethesda, Maryland) is

quoted asking, in essence:

what's new? Isn't this

just the 30-year-old

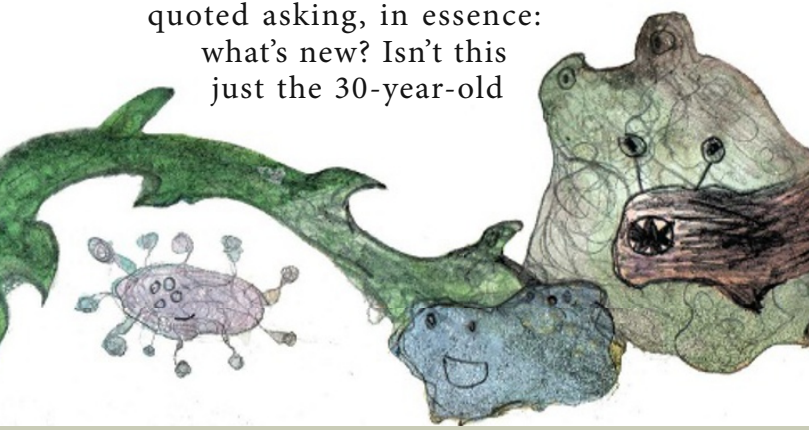

field of genetic engineering sporting a catchier trademark?

There is one disappointment. The book only incompletely conveys why efforts to rebuild life from the ground up ('synthesis') offer new avenues for discovery that those dissecting life from the top down ('analysis') do not.

The analytical approach to biology was born a few centuries ago, when those wishing to answer the question, 'what is life?', realized that observation alone was insufficient. Their investigations began by killing some unfortunate organism. After dissecting the spilled guts, tissues were named, maps were drawn and parts were catalogued. Much was learned; much of it practical. But the essence of 'life' did not emerge. With the invention of microscopes, the dissection went further, to cells. This time a new theory (cell theory) did emerge. As Regis' book emphasizes, cells are even today viewed as a defining attribute of life.

The so-called 'age of biology' came not from biologists but from chemists, who carried the dissection of living matter further. Karl William Scheele, in the late eighteenth century, crystallized the first organic molecule (barium lactate) from sour milk, and realized that the molecular parts of living organisms could be analysed. This led to structure theory, which holds that the arrangement of atoms in constituent molecules determines the behaviour of all matter. Biological chemists spent the next 150 years figuring out atomic arrangements in every biomolecule they could get their hands on, even DNA.

An unbroken line runs from Scheele to the human genome. It involves great technological innovation, but no conceptual innovation that can be thought revolutionary. Even Venter's personal genome is nothing more than a map of how its atoms of carbon, oxygen, hydrogen, nitrogen and phosphorus are arranged.

Even if the analytical strategy applied to biology is ever completed, biology will remain hollow. Living systems cannot be explained solely as a series of molecular structures, even when their interactions are described mathematically (as attempted in systems biology). Reflecting this, microbiologist Carl Woese wrote that the "strange claim by some of the world's leading molecular biologists that the human genome is the holy grail of biology is a stunning example of a biology that has no genuine guiding vision".

Synthesis offers a different strategy. The deliberate creation of new forms of matter from the bottom up, rather than the top down, gives us new ways to test nature. Chemists today use synthesis routinely. Having benefited from being first to gain the tools, they tested structure theory by building molecules with structures designed to target predictions of the relationship between molecular structure and behaviour. In a virtuous circle, they simultaneously built up their molecular toolkit and improved structure theory, further empowering synthesis. Chemists know that if one truly understands a phenomenon, one should be able to synthesize another, different system that generates that phenomenon.

Because building something requires a deep understanding of its parts, synthesis also stops scientists from fooling themselves. Data are rarely collected neutrally during analyses by researchers, who may discard some, believing the data to be wrong if they do not meet their expectations. Synthesis helps manage this problem. Failures in understanding mean that the synthesis fails, forcing discovery and paradigm change in ways that analysis does not.
Sustainable Fashion and Textiles: Design Journeys

by Kate Fletcher (Earthscan, $\$ 48.95, \notin 24.95$ )

Fashion is ephemeral by nature, but Kate Fletcher describes how clothing manufacture could be turned into a sustainable industry. Her detailed book assesses systems as well as products, examining possible solutions from raw material to final design.

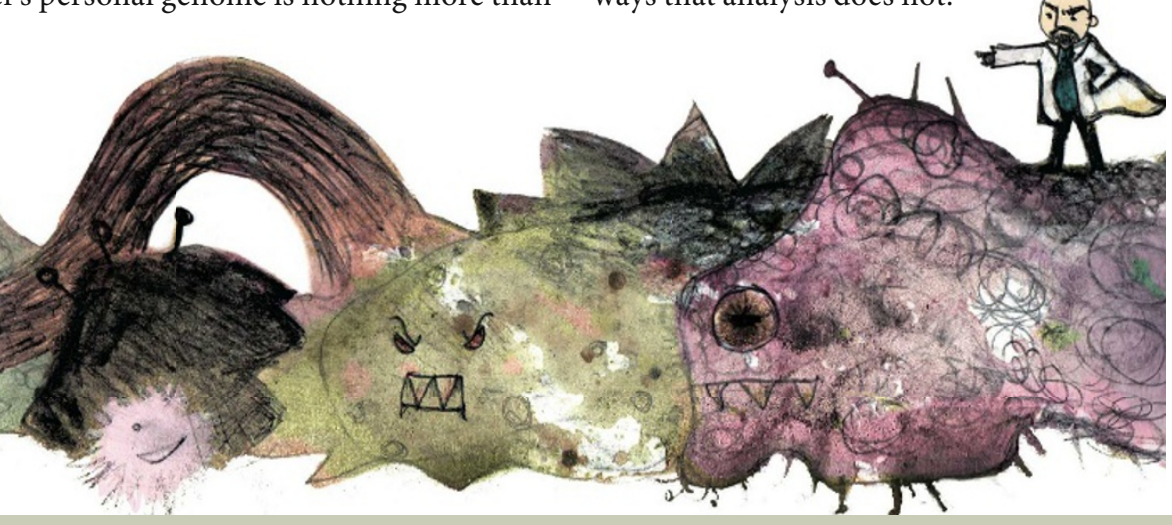

.

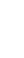


Now that genetic engineering is available, biologists are benefiting. By attempting to create synthetic genetic systems, we will learn more about how natural genetic systems work; by attempting to create synthetic metabolisms, we learn about how natural metabolisms work; by attempting to create synthetic regulatory circuits, we learn about how natural regulatory circuits work.

Will we ever understand what life is? Just as with Schrödinger's book, Regis' text will not be the last word. It is, however, a good place for a lay reader to start, one who welcomes the ambition of its title.

Steven Benner is a distinguished fellow at the Foundation for Applied Molecular Evolution and the Westheimer Institute for Science and Technology, Gainesville, Florida 32601, USA, and co-author of The Limits of Organic Life in Planetary Systems.

\section{Bottling the nuclear demon}

\section{Why Nuclear Disarmament Matters by Hans Blix}

MIT Press: 2008.97 pp. \$14.95, £9.95

\section{On Nuclear Terrorism \\ by Michael Levi \\ Harvard University Press: 2007. 210 pp. \\ $\$ 24.95, \notin 16.95$}

\section{Martin van Creveld}

Right or wrong, nuclear proliferation is much in the news. These two works tackle the problem head on. The first is a somewhat emotional call to prevent proliferation from proceeding further and, if possible, to reverse it. The second deals with some of the problems to which it may give rise.

To the readers of Nature, as well as anybody who is familiar with the origins of the second Iraq War, Hans Blix needs no introduction. In 2002-04, the elderly, genial Swedish diplomat, former foreign minister and former head of the International Atomic Energy Agency, found himself at the head of the UN Monitoring, Verification and Inspection Commission (UNMOVIC), charged with finding weapons of mass destruction in Iraq. Announcing that he had failed to discover any and that they almost certainly did not exist, he had to confront the full wrath of the Bush administration - a story that throws an ugly light on that administration while showing Blix himself in a very positive one.

A reader looking at the title of Blix's new work might be forgiven for thinking that he provides a retrospective account of several decades-worth of effort to put the nuclear demon back into the bottle from which it had escaped. He does nothing of the kind. First, contrary to his promise, he does not focus on nuclear weapons alone but widens the discussion - and, to my mind, weakens his case - by including chemical and biological ones too. Second, part of the book has little to do with nuclear disarmament but constitutes a polemic against the Bush administration's attempt to develop a national strategy based on pre-emption. Given how slim the volume is - in reality, it is just a brochure - this leaves little room for a serious discussion of nuclear disarmament, why it matters and what steps towards its realization should be taken next.

Furthermore, Blix is what the Germans call a Gutmensch - a do-gooder. From his perch in lucky Sweden, he observes the world with a benign smile and gently seeks to teach other benighted people how to improve it. One may certainly respect this position. On the other hand, it is neither the only one possible nor necessarily the one best suited for dealing with future nuclear-armed Adolf Hitlers, Joseph Stalins, and, yes, Saddam Husseins as well.

To put it bluntly, Blix is no strategist. As he himself comes very close to saying at the beginning of this book, he thinks in terms of morality and well-being, not of power. Not once does he mention deterrence. In other words, the fact that, had it not been for nuclear-weapons proliferation, World War Three might very well have broken out long ago and perhaps obliterated both his native country and himself.

A much younger man than Blix, Michael Levi is almost unknown. The cover of his book merely says that he is "Fellow for Science and Technology at the Council on Foreign Relations, New York". From an Internet search, we learn that he is an academic who has worked here and there and published this and that. Yet anyone who reads his work cannot but be impressed by his deep understanding of nuclear terrorism and the possibilities of dealing with it.

Levi's work is written in a calm, unemotional and somewhat dry manner. Those looking for hair-raising accounts of how

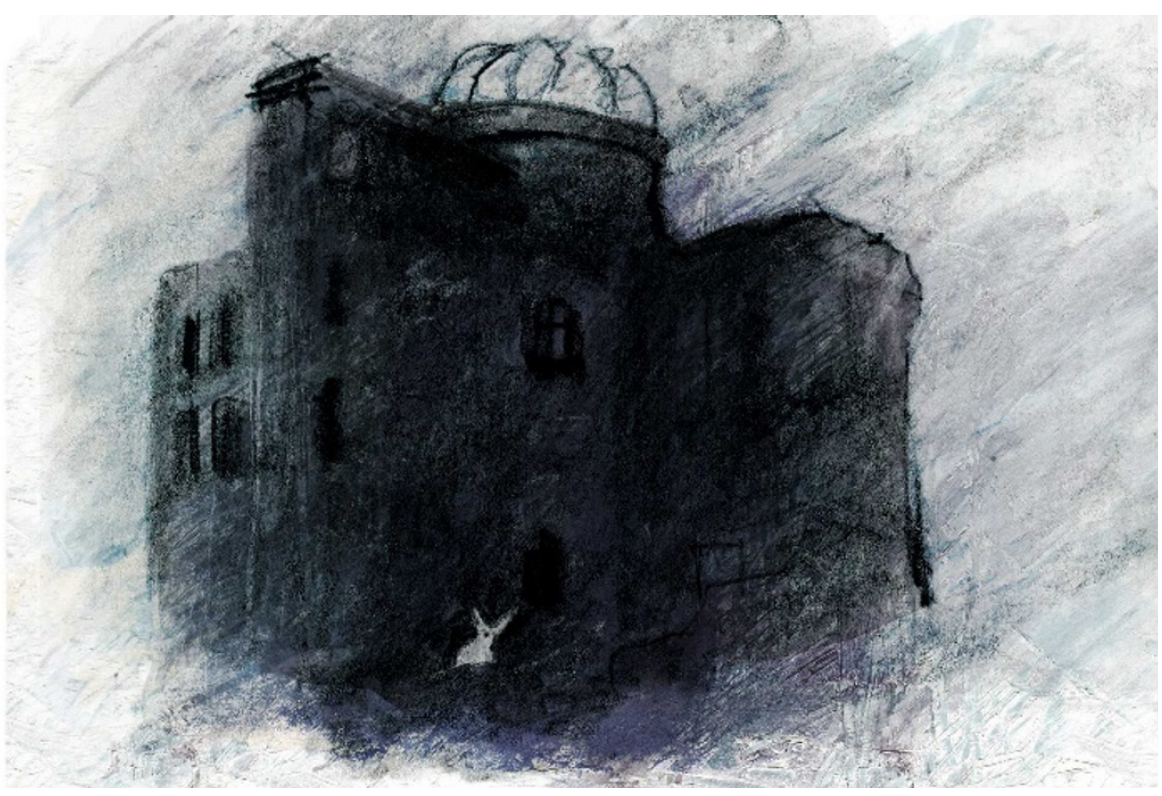

Doomsday Men: The Real Dr Strangelove and the Dream of the Superweapon

by P. D. Smith (Allen Lane, $€ 8.99$ )

In the 1950s, humans became capable of destroying life. Smith describes the first weapons of mass destruction and how the doomsday bomb became a symbol of science's destructive power. "The book is as much a history of modern science as of modern weaponry", wrote Gregg Herken (Nature 448, 868; 2007).

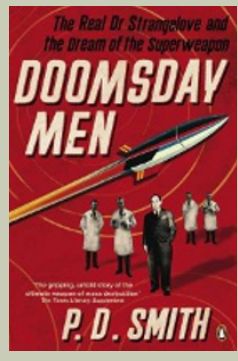

The Soulful Science: What Economists Really Do and Why It Matters

by Diane Coyle (Princeton Univ. Press, $\$ 19.95$ ) Economics is not a dry science but a human one, says Coyle. By incorporating psychology, evolution and complexity, economists are in the best position to model human society. Frances Cairncross wrote: "To understand how the big ideas of the past half-century fit together ... read this book" (Nature 447, 1057; 2007).

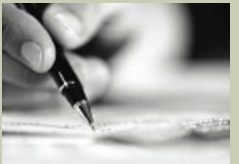

The Soulful Science what r:acrmbis Roully no an vilye r. vall DIANE COYLE 